\title{
Survey on mechatronic engineering: A focus on design methods and product models
}

\author{
Chen Zheng, Matthieu Bricogne, Julien Le Duigou, Benoît Eynard* \\ Université de Technologie de Compiègne, Department of Mechanical Systems Engineering, CNRS UMR7337 Roberval, CS 60319, 60203 Compiègne Cedex, France
}

\section{A R T I C L E I N F O}

\section{Article history:}

Received 8 October 2013

Received in revised form 3 May 2014

Accepted 31 May 2014

Available online 19 June 2014

\section{Keywords:}

Mechatronic engineering

Systems engineering

Design methods

Product models

Product Lifecycle Management

Integrated design

\begin{abstract}
A B S T R A C T
According to the principles of concurrent engineering and integrated design, engineers intend to develop a mechatronic system with a high level integration (functional and physical integrations) based on a well-organised design method. As a result, two main categories of issues have been pointed out: the process-based problems and the design data-related problems. Several approaches to overcome these issues have been put forward. To solve process-based problems, a dynamic perspective is generally used to present how collaboration can be improved during the mechatronic design. For design data-related problems, solutions generally come from product models and how to structure and store the data thanks to the functionality of data and documents management of Product Lifecycle Management systems. To be able to assess design methods and product models, some criteria are proposed in the paper and used to evaluate their added value on integrated design of mechatronic system. After this assessment, main outcomes which focus on the combination of design method and product model for improving the design of mechatronic system are finally discussed.
\end{abstract}

(c) 2014 Elsevier Ltd. All rights reserved.

\section{Introduction}

The term "Mechatronics" originated at the Yaskawa Corporation from the combination of mechanics and electronics, to describe the integration process of four disciplines: mechanics, electronics, computing and automatic control [1]. Because of the technology development, mechatronics becomes the synergistic integration of physical systems with information technology (IT) and complex decision-making in the design, manufacture and operation of industrial products and processes [2]. In this section, mechatronic system specificities will be introduced. Due to these specificities, issues linked to mechatronic systems design will be presented.

\subsection{Mechatronics and integrated design}

Products are becoming increasingly complex and integrating technologies from several fields, such as mechanical engineering, electronic/electrical engineering and software engineering. Mechanical systems developed since the 1980s have thus evolved from electro-mechanical systems with discrete electrical and

* Corresponding author. Tel.: +33 3442345 78; fax: +33 344235229 .

E-mail addresses: chen.zheng@utc.fr (C. Zheng), matthieu.bricogne@utc.fr (M. Bricogne), julien.le-duigou@utc.fr (J. Le Duigou), benoit.eynard@utc.fr (B. Eynard). mechanical parts to integrated electronic-mechanical systems with sensors, actuators, and digital micro-electronics. These integrated systems, composed of hardware and software modules, are generally called mechatronic systems $[3,4]$.

Mechanical system has started to integrate electrical and control functions to become a real mechatronic system, and several evolution steps have been generally observed. Fig. 1 [5] presents this evolution, the different involved engineering disciplines and the overlaps between them. First, Actuators (A), represented on the right angle of the triangle, are added. They are in charge of managing actuation forces and speed. It can be regarded as the first combination of electronics and mechanics disciplines. To supply power to these actuators, external power is needed and generally provided by electrical engineering disciplines. Second, the Embedded control (E), comes "with the goal of an automatic or more reproducible process" [5]. On the top angle of the triangle, embedded control can be considered as the overlap between the electronic and software disciplines. Third, the Sensors (S), on the left angle, allow the system to get detailed information about the status of the system and to fulfil correctly to the various environmental conditions. It is considered as the overlap between the mechanics and IT disciplines. Finally, the Communication (C) is now considered as the central piece of the system, especially for distributed systems. It allows integrating the sub-system into the whole product/system. 


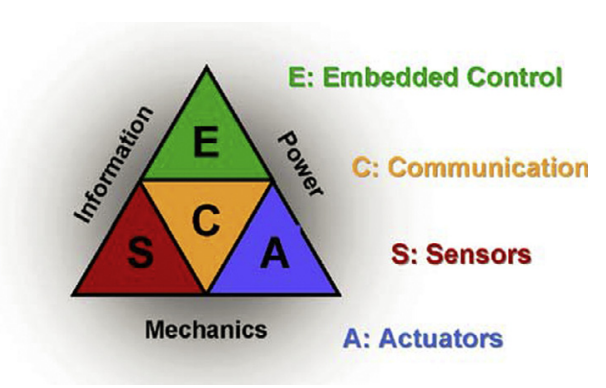

Fig. 1. Mechanical systems integrating electronics in interaction with information and power [5].

This kind of evolution allows fulfilling much more functions compared to a pure mechanical system or pure electronic system. "But all this could still be just called an automated system; mechatronics means more than this" [5]. Mechatronic systems are the resulting product of a global concurrent engineering or integrated design approaches [6,7]. To achieve such integrated design, Abramovici and Bellalouna describe the problems to overcome as "Process-based problems" and "Design data-related problems" [8].

According to Abramovici and Bellalouna, "Process-based problems" are linked to the coordination and the synchronisation of the "different disciplines, specific development processes, activities, tasks and results across all fields is not sufficiently supported", but also to the fact that complex "coherences and interactions between the disciplines are considered in a late development phase". Furthermore, "comprehensive integration, configuration, change and release management across all disciplines is little or barely supported" [9].

The second kind of difficulties encountered during design of mechatronic systems, called "Design data-related problems" [9], is related to the edition and management tools heterogeneity. For example, mechanical designers use Computer Aided x (CAx) applications to support the product development process. The data generated are generally stored in Mechanical Product Data management (M-PDM) systems while electrical and electronic designers use Electrical/Electronic Engineering Solutions (EESs) to create data which are stored in Electrical PDM (E-PDM). Software designers use development solutions to create source code that is managed thanks to Software Configuration Management (SCM) or Concurrent Versions System (CVS) systems. This heterogeneity in terms of product data, data models and data formats leads to several problems that can be summarised as no adequate multi-disciplinary integration of product data [10].

All these multi-disciplinary integration issues could have some negative impacts on the final integration of the mechatronic system. Fig. 2 presents several levels of integration for a mechatronic system. The first kind of integration is called "separated components". In this case, components are designed separately and are just incorporated in the same system thanks to cable. The second level of integration corresponds to the concept of "joined components". The mechanical component will be designed in order to place the electrical and/or the electronic components in juxtaposition with each other. Distances between components have been reduced. The third kind of integration is called "included": electronic components are spread out into the whole system, but this kind of integration does not achieve a "real" integration. Finally, the ultimate integration level is the "merged" components: electronics is integrated as close as possible to the mechanical and electrical components. Parts are gathered in a consistent and functional manner and mechanical parts can also be used as signal transmitter. The contributions of this integration are various:

- Physical integration: spatial and weight optimisations.

- Functional integration: detection, communication, control/ information processing allow the system to provide new functionalities and to be reliable.

In this section, the design of mechatronic system, the issues related to multi-disciplinary integration and their possible effects on the final integration of mechatronic system have been discussed. The following section describes the focus of the paper and the way the survey will be organised.

\subsection{Focus of the paper and survey organisation}

To achieve the optimal integration for the final mechatronic system, several problems have to be overcome. As described in the previous section, these problems could be divided into two main categories, the "Process-based problems" and the "Design data-related problems". To overcome these problems, several efforts have been presented in different communities. The paper aims at presenting some of these approaches. In Section 2 the identified collaboration challenges are presented and discussed in detail. For a better understanding of the added value of every methods or models, several specific collaboration criteria based on these collaboration challenges are also exposed in this section. Section 3 gives a review on existing design methods used in mechatronic engineering. They are all considered as a potential solution to the "Process-based problem", focusing on the dynamic of the collaboration. Section 4 presents various product models enabling mechatronic design and disciplines integration, dedicated to "Design data-related problems". Section 5 introduces the assessment of studied design methods and product model according to the specific criteria derived from the collaboration challenges in Section 2. Section 6 proposes a synthesis and discussion on the main outcomes obtained. Last, the concluding section summarises the proposed survey and key ideas of the paper.

\section{Collaboration challenges in design of mechatronic system}

As depicted previously, an "integrated design" for mechatronic system embodies in two aspects: a design process with high-level multi-disciplinary collaboration and a mechatronic system with
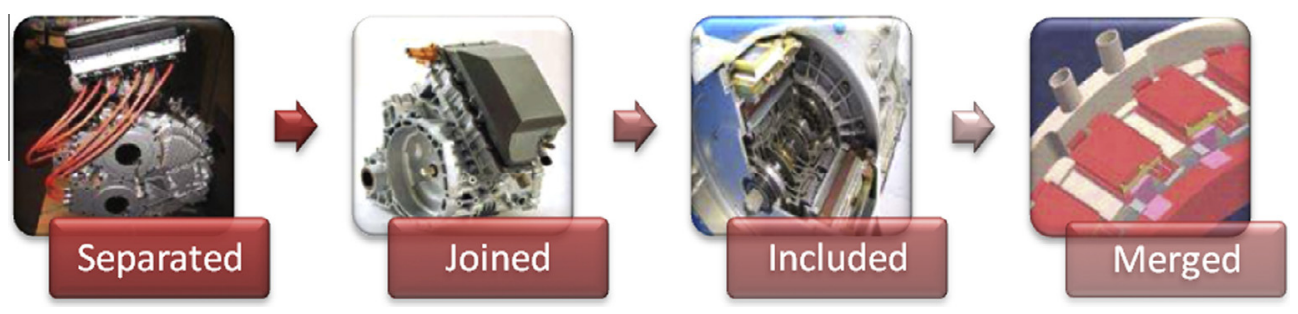

Fig. 2. The different integration levels in mechatronic systems [11]. 
high-level functional and physical integration. The former raises "Process-based problems" while the latter brings up "Design data-related problems". However, neither academia nor industry has yet provided explicit solutions to solve such two kinds of problems due to some collaboration challenges in design of mechatronic system. These collaboration challenges related to such problems will be discussed in more detail.

\subsection{Process-based problems}

One strong particularity of design process of mechatronic system is that it requires a multi-disciplinary and holistic development process. Although efforts that address design process-based problems have been done, some challenges are still remaining, such as:

- Traditional sequential design process can still be considered as a standard in industry.

- There is a lack of effective methods to support multi-disciplinary design during the whole design process.

- There is a lack of effective tools to support the sharing and exchange of design data among engineers.

By analysing these challenges, three criteria to evaluate current design methods can be proposed. They correspond to the major encountered industrial problems during the multi-disciplinary design process. These criteria correspond to the challenges proposed previously and affect many of the problems during the multi-disciplinary design process:

- Concurrent engineering.

- Macro level collaboration.

- Micro-level collaboration.

These criteria are more precisely described in the next section.

\subsubsection{Concurrent engineering}

Mechatronic design activities often depend on separated design tools and data, so traditional method, like sequential design process, remains a standard in industries. However, this design process has proven to be unsuitable for modern mechatronic design because it increases the design cost and development leading-time. Concurrent engineering is a work methodology based on the parallelisation of design tasks [6]. It is of great importance as the design cost and development lead-time can be drastically reduced through the design tasks carried out at the same time [12]. However, how to organise the concurrent tasks in order to achieve the coordination of resources and project team members is still a critical issue, especially to get a fully integrated design [7].

\subsubsection{Macro level collaboration}

As mentioned by [4], mechatronic systems are often built from discipline homogeneous subsystems (mechanics, electrics/electronics and software). The typical approach for the design of mechatronic system is carried on in a concurrent manner with a special focus on the subsystems and the interfaces among them [13]. The macro level collaboration emphasises such discipline homogeneous collaboration. It not only focuses on the assembly of the subsystems from different specific design disciplines, but pays special attention to the discipline interfaces among them as well.

\subsubsection{Micro-level collaboration}

The design process of mechatronic system should also focus on the collaboration of the different engineers or designers, such as communication among designers, data sharing and exchange. Such collaboration among the individuals is called in this paper micro-level collaboration. Traditionally, the micro-level collaboration is often performed thanks to informal exchanges supported by e-mail, phone or regular meeting.

\subsection{Design data-related problems}

A large number of product data will be created and managed throughout the whole product lifecycle, especially during the process. The main objective of product model is to support Product Data Management (PDM) functions of Product Lifecycle Management (PLM). Product model includes all the information that can be accessed, stored, served and reused by stakeholders and it can help the mechatronic system to achieve a high-level functional and physical integration. However, diversity of data from different disciplines also brings about some challenges to the design of mechatronic system such as:

- Organisation of design process by making use of product models.

- Overlooking the importance of the interfaces' information between the subsystems of mechatronic system.

- Lack of an effective support for the data exchange among designers.

- Representation of one temporal dynamic of product during the whole design process.

- Representation of the design changes for a product family.

By examining these challenges, five criteria to evaluate current product models can be identified. These criteria will be grouped in the same order as the challenges proposed previously:

- Organisational interface.

- Macro level interface.

- Micro-level interface.

- Vertical change.

- Horizontal change.

These criteria are more precisely described in the next section.

\subsubsection{Organisational interface}

Although the process model has been taken into account by several product models, how to use product model to direct the design process of mechatronic system has still been a critical issue. Organisational interface is used to guide the design tasks and support the collaboration throughout the whole design process. The organisational interface affects the design process of mechatronic system in two aspects. On one hand, the organisational interface helps to transform the users' requirements into the principal solutions in the preliminary design phase to assist designers in making decision. On the other hand, it notifies the designers that their discipline-specific solutions have to be taken into account by other disciplines for their own solutions to manage conflicts between them. In summary, organisational interface can help engineers have a well-organised concurrent engineering for mechatronic system design, focusing on possible inconsistencies or poor integration.

\subsubsection{Macro level interface}

During the process of mechatronic system design, a great number of subsystems are defined by specific disciplines and are under development by different engineers. With the purpose of two subsystem to be interconnected, there must be compatible interfaces in mechanical, electronic/electrical and software disciplines [14], which are called in this paper macro level interfaces. Such interfaces describe the associations between subsystems, both to indicate their inter-dependence and to provide high-level guidance 
for how subsystems should be joined in the final product [15]. The macro level interfaces can help engineers to achieve the basics for integration of the subsystems. By comparing the description of macro level interface with that of macro level collaboration described previously, macro level interface envisions to be an effective support for macro level collaboration during the design process of mechatronic design.

\subsubsection{Micro-level interface}

The engineers need another kind of interface which allows them to exchange and share information or data from other disciplines during the process of mechatronic design. It intends to help designers to collaborate or coordinate by sharing information through formal or informal interaction [16]. Micro-level interface provides an effective mean to solve this issue. Because micro-level interface has been built in many information and distributed computer systems to support the process of mechatronic design, it fosters a better micro-level collaboration.

\subsubsection{Vertical change}

Vertical change focuses on how to manage the product's temporal dynamics of the product definition during the product development process. Mechatronic design is a dynamic process and a static product model is no longer suitable for mechatronic design. Such dynamic process mainly embodies two aspects: on one hand, product data are specified as versioned to take into account the temporal dynamics of the product definition; on the other hand, the product definition may be modified from time to time due to customers' requirements and market changes. Because the mechatronic system is a combination of mechanical, electronic/electrical and software technology, a modification in any discipline will lead to a completely different design process. The product model of mechatronic system should evolve dynamically according to the progress of design process.

\subsubsection{Horizontal change}

Horizontal change focuses on how to manage product families' data. The development of new product based on the successful design of its predecessors brings several benefits for the company and customers. First, the development approach of product family reduces lead-times and costs due to the development background of the predecessors. Second, the reliability of the new product can be dramatically increased thanks to the predecessors' successful design. Last, extensive versions can be easily derived from the predecessors [17].

Fig. 3 presents vertical and horizontal change. The vertical arrow represents the vertical change while the horizontal arrow represents horizontal change.

\subsection{Criteria of design methods and product models}

Generally speaking, design knowledge can be classified into two categories: design process knowledge and product knowledge [16]. The collaboration challenges related to the process-based problems (process knowledge) and design data-related problems (product knowledge) have been discussed in this section. As depicted in the previous subsections, organisational interface, macro level interface and micro-level interface are considered as effective supports for concurrent engineering, macro level collaboration and micro-level collaboration separately. Fig. 4 shows the relationship between the criteria of concurrent engineering and organisational interface, macro level collaboration and macro level interface and micro-level collaboration and micro-level interface.

Another two criteria of product models, vertical change and horizontal change were subsequently proposed. The criteria and their descriptions are summarised in Table 1. Current design methods and product models will be presented and assessed by the criteria in the following sections in more detail.

\section{Design methods for mechatronic engineering}

Design of mechatronic system requires a multi-disciplinary collaboration. To deal with such multi-disciplinary design issue, since the late 1950s and the early 1960s, system engineering has been proposed as an interdisciplinary approach and means to enable the realisation of successful system [18]. In the 1980s, some system design methods, such as waterfall model [19], spiral model [20] and V-model [21] were widely used for systems engineering. A design method can help the engineers from different disciplines to enable their collaboration for the increasingly complex tasks of systems engineering [22]. However, a design method specially adapted for design of mechatronic system was not put forward at that time. After the 1980s, the use of microcomputer technology and software determines functions were integrated in mechatronic

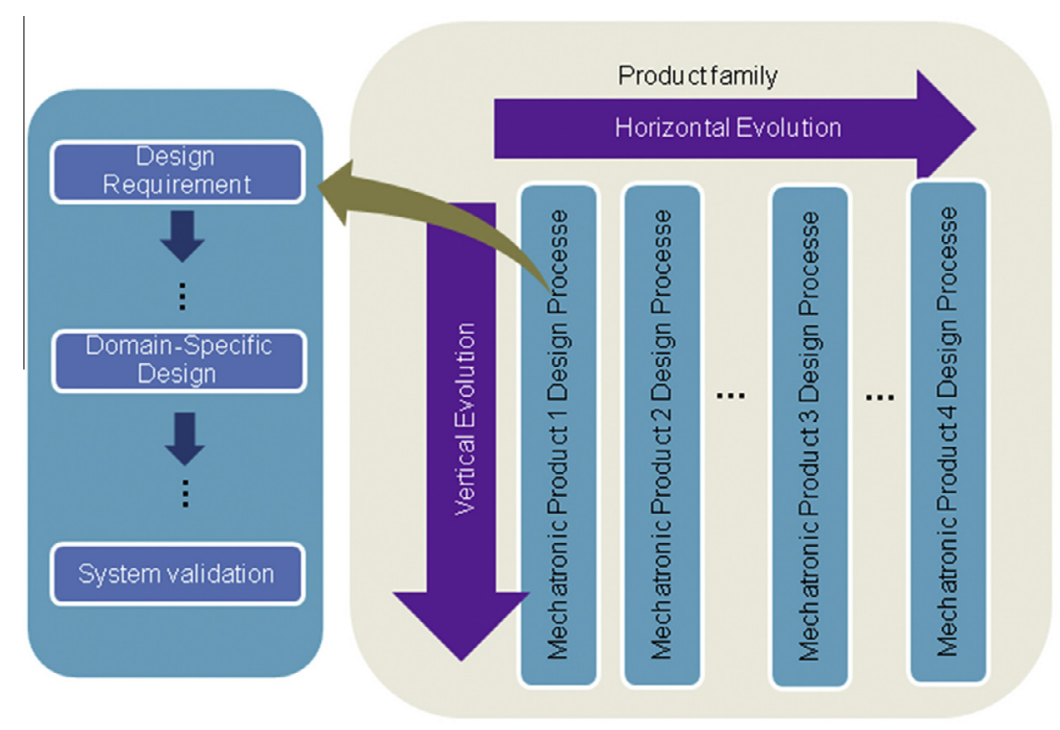

Fig. 3. Product change: horizontal vs. vertical evolutions. 


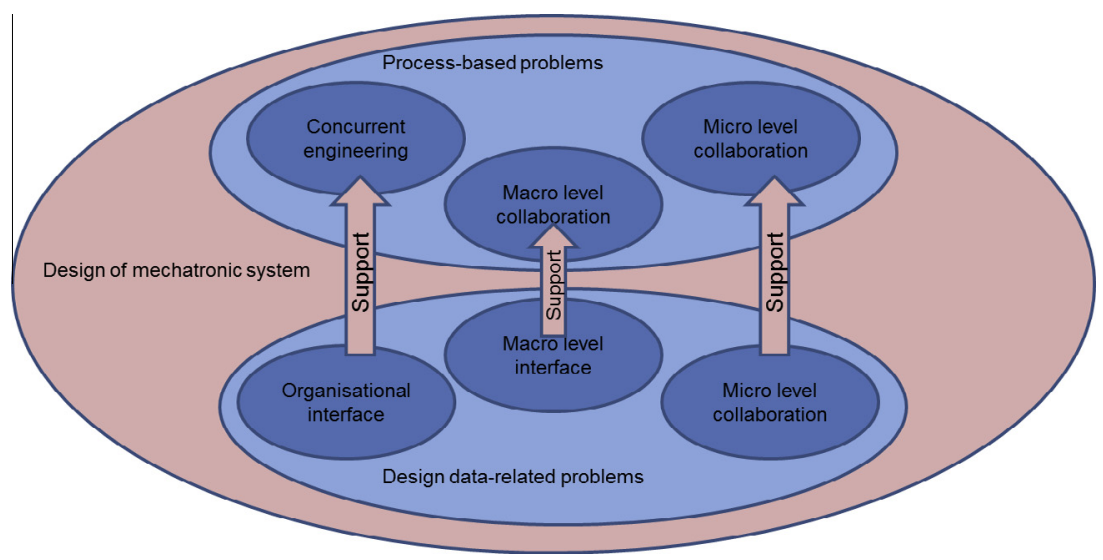

Fig. 4. Relationship between the criteria of product models and those of design methods.

Table 1

Summary of criteria and their descriptions.

\begin{tabular}{|c|c|c|}
\hline $\begin{array}{l}\text { Contribution } \\
\text { type }\end{array}$ & Criterion & Description \\
\hline \multirow[t]{3}{*}{$\begin{array}{l}\text { Design } \\
\text { methods }\end{array}$} & $\begin{array}{l}\text { Concurrent } \\
\text { engineering }\end{array}$ & A work methodology based on the parallelisation of design tasks \\
\hline & $\begin{array}{l}\text { Macro level } \\
\text { collaboration }\end{array}$ & $\begin{array}{l}\text { Discipline homogeneous collaboration which focuses on the assembly of the subsystems from different specific design disciplines } \\
\text { and the interfaces among them }\end{array}$ \\
\hline & $\begin{array}{l}\text { Micro-level } \\
\text { collaboration }\end{array}$ & $\begin{array}{l}\text { Collaboration of the different engineers, such as communication among designers, data sharing and exchange and design } \\
\text { knowledge management }\end{array}$ \\
\hline \multirow[t]{5}{*}{$\begin{array}{l}\text { Product } \\
\text { models }\end{array}$} & $\begin{array}{l}\text { Organisational } \\
\text { interface }\end{array}$ & $\begin{array}{l}\text { Interface which assists designers in making decision and managing conflicts between them in order to help them have a well- } \\
\text { organised concurrent engineering for design of mechatronic system }\end{array}$ \\
\hline & $\begin{array}{l}\text { Macro level } \\
\text { interface }\end{array}$ & $\begin{array}{l}\text { Interface which describes the associations between subsystems and can help engineers to achieve the basics for integration of the } \\
\text { subsystems }\end{array}$ \\
\hline & $\begin{array}{l}\text { Micro-level } \\
\text { interface }\end{array}$ & $\begin{array}{l}\text { Interface which allows engineers to exchange and share information or data from other disciplines and helps designers } \\
\text { collaborate or coordinate through formal or informal interaction }\end{array}$ \\
\hline & Vertical change & Management of the product's temporal dynamics of the product definition during one product's development process \\
\hline & Horizontal change & Management of product families' data \\
\hline
\end{tabular}

system [3]. The continuously growing complexity of mechatronic system requires a more integrated design than ever. Therefore a number of mechatronic design methods have emerged to meet the need of collaboration during the design process of mechatronic system. Derived from approaches such as the traditional sequential design [23], the concurrent engineering [24] or the much recent lean product development [25], many design methods for mechatronic engineering have been proposed, but these design methods still remain poor to support the technology integration and multidisciplinary perspectives in mechatronic design. A non-exhaustive list of design methods is presented hereafter.

\subsection{Sequential design process}

The traditional approach for the design of mechatronic system is called sequential design process. In this design process, the main concerns of the mechanical view are reliability and technical performance of the system. The control view of the system is then designed and added to provide additional performance or reliability and also to correct undetected errors in the design. As the design steps occur sequentially, this approach is called sequential design model [4]. The principle of the sequential design process is that each new design task must be started when the previous one has been finished ([4] - Fig. 5). For example, the mechanical design has to be "frozen" before proceeding to the design of control software [26].

Obviously, the sequential design process can help the executive manager to have a global view about the whole design. However, it is not suitable for modern industrial company any longer. Firstly, this whole duration of the design process is very long since the design in each discipline has to be carried out one after another. Consequently, this approach usually does not lead to optimal overall behaviour. Secondly, the software plays a key role for the system's performance, so it must be considered during the whole design process. As the software design is often executed as the last task in the sequential design process, this process cannot reflect the importance of software in modern mechatronic design. In order to solve the problems brought by sequential design process, several design approaches which allow concurrent engineering have been put forward. V-model, for instance, will be presented in the next section.

Table 2 shows an evaluation of the sequential design process according to the three criteria above proposed. Obviously, the sequential design process cannot support concurrent engineering. Fig. 5 shows that there are explicit links between subsystems (sensor and actuator, detailed modular, control system and etc.) during the design process. So the macro level collaboration can be performed in such design method. But it does not provide an effective support for the collaboration among different engineers. So the micro-level collaboration has not been developed in this design method.

Thus, the sequential process leads to negative effects on further developments of the mechatronic systems. In order to solve the problems brought by sequential design process, several design approaches which allow concurrent design have been put forward. $\mathrm{V}$-model, for instance, will be presented in the next section. 


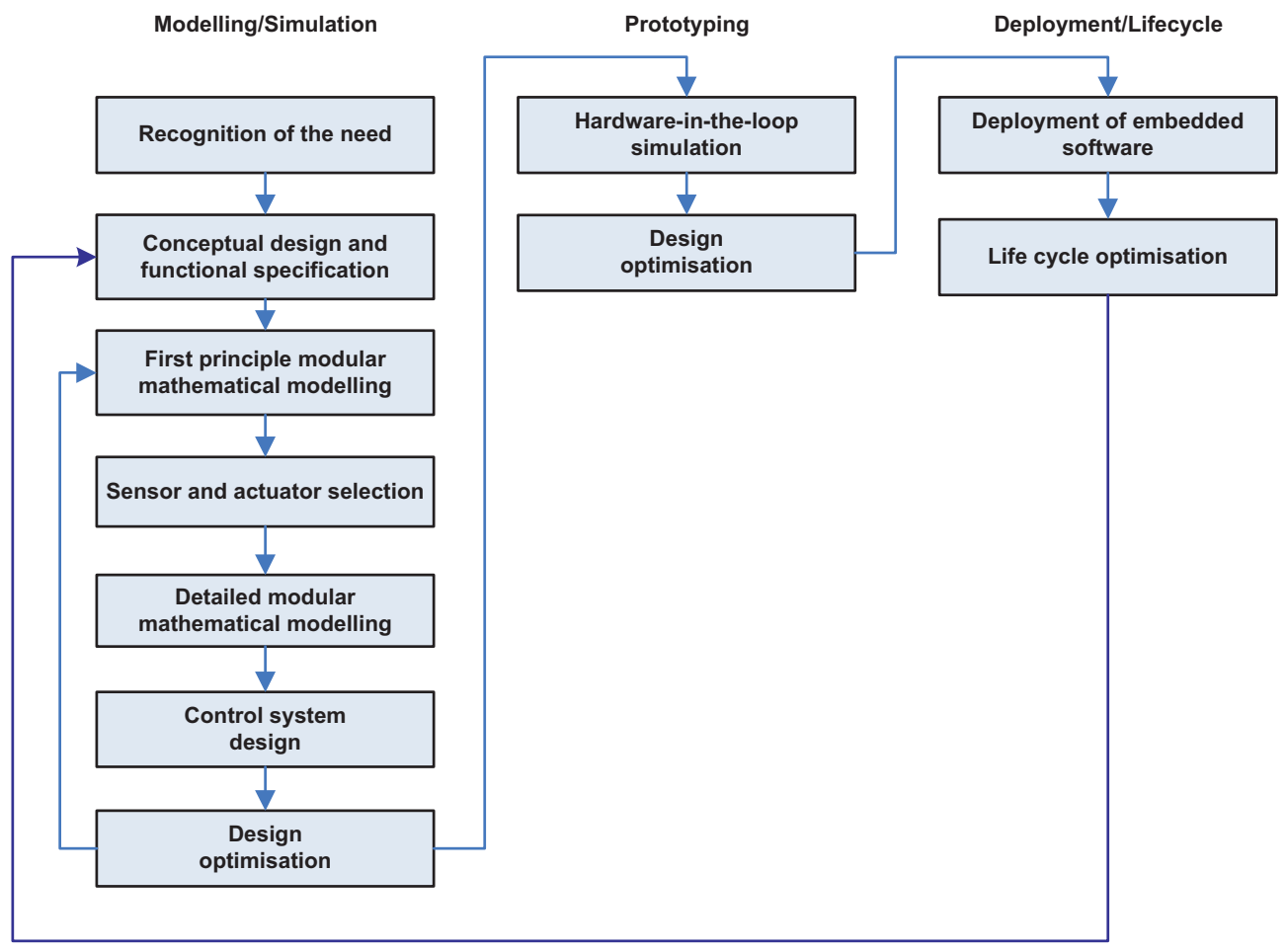

Fig. 5. Sequential design process [4].

Table 2

Evaluation of sequential design process.

\begin{tabular}{|c|c|c|}
\hline Design method & Sequential design process & \\
\hline $\begin{array}{l}\text { Concurrent } \\
\text { engineering }\end{array}$ & The design steps occur sequentially & No \\
\hline $\begin{array}{l}\text { Macro level } \\
\text { collaboration }\end{array}$ & There are explicit links between subsystems & Yes \\
\hline $\begin{array}{l}\text { Micro-level } \\
\text { collaboration }\end{array}$ & $\begin{array}{l}\text { It does not support the collaboration of different } \\
\text { engineers }\end{array}$ & No \\
\hline
\end{tabular}

\subsection{V-model}

The V-model presents a general flow for the product development process. It starts with identification of user's requirements. Once the requirements have been taken into account, they are then placed under project control (upper-left) and the V-model will end with a user-validated system (upper right). In order to arrive to the final product, each stage of the product definition should be tested [21].

During the High-level Design and Detailed Design phases on the axis of "Decomposition and Definition" (Fig. 6), subsystems of the system are identified and decomposed further into component. Requirements are allocated to the system components and interfaces are specified in detail. Therefore the design tasks for different subsystems can be executed in parallel. The main purpose of the axis of integration and recomposition is to validate each corresponding stage in the part of decomposition and definition in Fig. 6 [21].

The V-model defines an integrated design process, and a concurrent engineering has been achieved in this model. As shown in Fig. 6, during the phase of implementation, the V-model simply divides the mechatronic system into software and hardware, ignoring the fact that the mechatronic system is the combination of

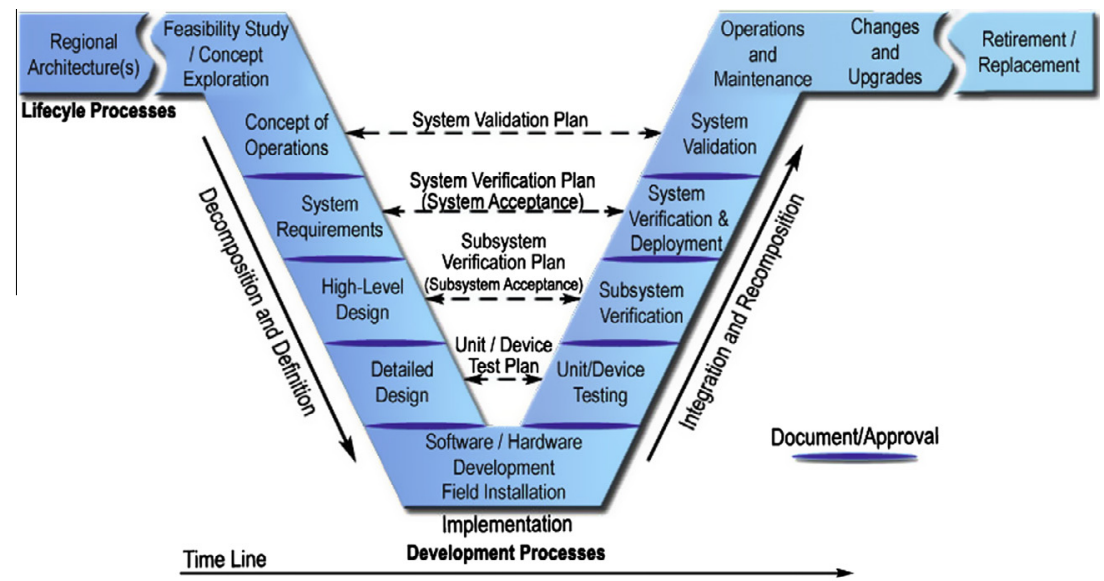

Fig. 6. V-model [27]. 
Table 3

Evaluation of V-model.

\begin{tabular}{|c|c|c|}
\hline Design method & V-model & \\
\hline Concurrent engineering & The design tasks for different subsystems can be executed in parallel during the Detailed Design phases & Yes \\
\hline Macro level collaboration & During the phase of Implementation, the V-model simply divides the mechatronic system into software and hardware & Partial \\
\hline Micro-level collaboration & It does not support the collaboration of different engineers & No \\
\hline
\end{tabular}

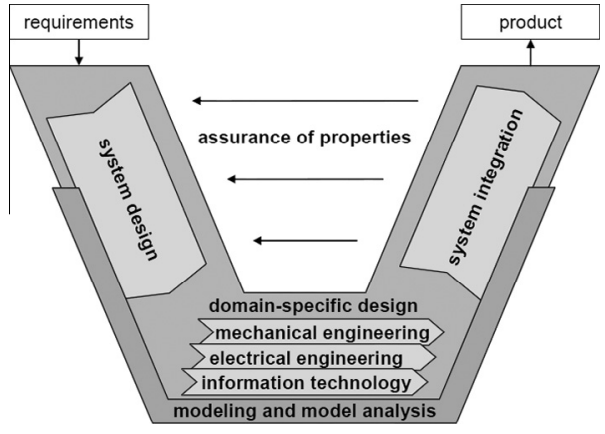

Fig. 7. VDI2206 [30].

mechanics, electronics and software. For that reason the macro level collaboration is partially performed in V-model. The collaboration of different engineers has not been mentioned in this design method. An evaluation of the V-model is shown in Table 3. The Vmodel provides a design process which is more integrated than sequential design process.

\subsubsection{VDI 2206}

The VDI guideline 2206 is a functional modelling methodology based on the $\mathrm{V}$-model. The functional modelling methodology means that different methods are used to define a model of any system by capturing and processing the information about its purpose and the functions of its components to fulfil the purpose [28].

The VDI guideline 2206 is developed and standardised by a VDI committee, a German engineers association. It represents a practice-oriented guideline for the systematic development of mechatronic system. Different from the VDI/VDE 2422 used for the design of mechanical and electrical components separately, the VDI 2206 provides the first neutral guideline for the design of mechatronic system [29].

The VDI guideline 2206 provides a useful frame for designing any kind of mechatronic system. It consists essentially of three elements [30]:

- The V-model on the macro-level.

- A general problem-solving cycle on the micro-level.

- Predefined process modules for handling recurrent working steps in the development of mechatronic systems.

The VDI guideline 2206 divides mechatronic system design into four major phases, called "system design", "domain-specific design", "system integration" and "assurance of properties" (Fig. 7).

The goal during the system design phase is to define a cross-discipline solution concept for the system. In this phase the overall function of the system will be divided into sub-functions.

The domain-specific design phase can be regarded as several parallel smaller design tasks. The results from the discipline-specific design are integrated to the complete mechatronic system in the phase of system integration.

The purpose of the assurance of properties phase is to make sure that the results of the system integration fulfil the solution concept defined during the phase of system design. If the system has to be improved, the design process will be repeated.

The modelling and model analysis lasts from the system design phase to the system integration phase. During process of modelling and model analysis, modelling technique and CAx applications will be used. In order to meet the some special requirements of complex mechatronic system, several variants of VDI 2206 have been proposed. A product development process which focuses on the degree of mechatronic product maturity is developed based on the principle of VDI 2206. In this variant, the mechatronic product is generally not produced within one macro cycle of V-model, but within many macro cycles as a continuous macro cycle. At the end of each macro cycle, a product with an increasing maturity, such as laboratory specimen, functional specimen and pilot-run product will be produced [31]. A mechatronic systems controlled by a PLC (Programmable Logic Controller) can be developed by another variant of VDI 2206. In this variant, because the information technology (developing the software for the PLC) and mechanical engineering (using CAD to design the geometry) has been identified as the major engineering domains for such mechatronic system, the domain "electrical engineering" is neglected [30].

The VDI 2206 provides a practice-oriented guideline for design of mechatronic system. Compared with the V-model, it unifies the domain-specific design more systematically (Mechanical engineering, electrical engineering and information technology), but the interfaces among the subsystems of different design domains do not arouse enough attention in this organisational method. Moreover, an explicit links between the different engineers does not exist in VDI 2206. An assessment of the VDI 2206 is shown in Table 4.

\subsubsection{RFLP method}

The RFLP approach is a specific V-model derived method particularly adapted to design of mechatronic system. It is implemented in the CATIA System $v 6^{1}$ software and can therefore be considered as a commercial approach. In this method, the descending branch of V-model is divided into 4 views: Requirement engineering view, Functional view, Logical view and Physical view [32].

In the requirement engineering view, users' requirements are clarified. These requirements can be described according to the $\mathrm{APTE}^{2}$ method or the SysML ${ }^{3}$ language.

In the functional view, the main functions of mechatronic system are presented. The language SysML or CATIA System Engineering can be used as the modelling tools in order to build the functional view.

In the logical view, the logical architecture of mechatronic system will be defined. Multi-disciplinary tools to model and carry out numerical analysis, such as Modelica ${ }^{4}$, Matlab/Simulink ${ }^{5}$ and bondgraphs ${ }^{6}$ can be used for the logical modelling of mechatronic system.

\footnotetext{
1 http://www.3ds.com/products-services/catia.

2 http://cabinet-apte.fr/.

3 http://www.omgsysml.org/.

4 https://www.modelica.org/.

5 www.mathworks.com.

6 http://www.bondgraph.org/.
} 
Table 4

Evaluation of VDI 2206.

\begin{tabular}{|c|c|c|}
\hline Design method & VDI 2206 & \\
\hline $\begin{array}{l}\text { Concurrent } \\
\text { engineering }\end{array}$ & The discipline-specific design phase can be regarded as several parallel smaller design tasks & Yes \\
\hline $\begin{array}{l}\text { Macro level } \\
\text { collaboration }\end{array}$ & $\begin{array}{l}\text { VDI } 2206 \text { unifies the domain-specific design more systematically, but the interfaces among the subsystems of different design domains } \\
\text { do not arouse enough attention }\end{array}$ & Partial \\
\hline $\begin{array}{l}\text { Micro-level } \\
\text { collaboration }\end{array}$ & It does not support the collaboration of different engineers & No \\
\hline
\end{tabular}

Table 5

Evaluation of RFLP method.

\begin{tabular}{|c|c|c|}
\hline Design method & RFLP method & \\
\hline $\begin{array}{l}\text { Concurrent } \\
\text { engineering }\end{array}$ & The RFLP method fully supports concurrent engineering & Yes \\
\hline $\begin{array}{l}\text { Macro level } \\
\text { collaboration }\end{array}$ & Multi-domain modelling methods are used to fully support the macro level collaboration in the logic view & Yes \\
\hline $\begin{array}{l}\text { Micro-level } \\
\text { collaboration }\end{array}$ & $\begin{array}{l}\text { In the physical view, the geometric definition of product, the schematic definition and the source code will be created, but the exchange } \\
\text { of information between software design and other disciplines remains a challenge and should be further developed }\end{array}$ & Partial \\
\hline
\end{tabular}

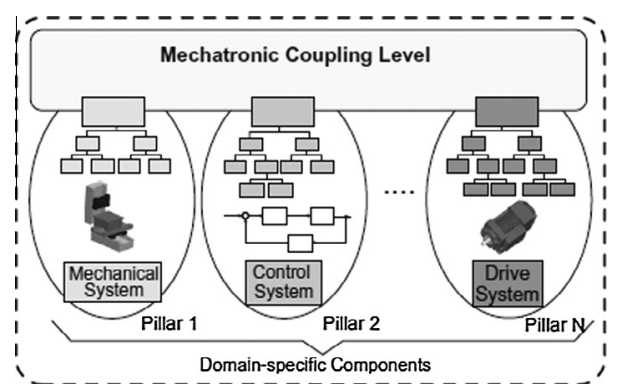

Fig. 8. Mechatronic system and model pillars [37].

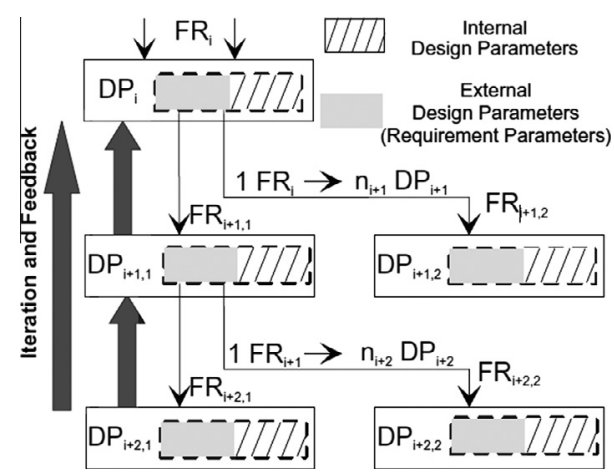

Fig. 9. Hierarchy of parameter [36].

In the physical view, the components, the geometric definition of product (Mechanical Computer Aided Design, M-CAD), the schematic definition (Electronic/Electrical Computer Aided Design, ECAD) and the source code (software) will be created. The 3D CAD applications and the analysis software, such as Simulia ${ }^{7}$ can be used. In this view, the difficulty of multi-disciplinary simulation is related to issues of interoperability between design and analysis applications, which will lead to difficulties to ensure multidisciplinary optimisation [33].

Table 5 shows an assessment of RFLP method.
Nowadays, the RFLP method has been integrated into CATIA/ ENOVIA v6. This CAx/PDM system provides functionalities for storing, sharing and exchanging certain types of data and information among the engineers of different disciplines, such as the data of MCAD and E-CAD [34]. But how to integrate the software source code remains a challenge.

Two organisational methods of V-model, VDI 2206 and RFLP methods have been presented in the sub-sections above. A last design method, called the hierarchical design method, is presented in the following section. This method can greatly reduce unnecessary iteration loops during the design process, especially for the complex mechatronic system.

\subsubsection{Hierarchical design method}

The hierarchical design method takes the integration of mechanical, electrical and electronic control and software aspects from the very beginning of the earliest design phase [35].

Mechatronic system can be broken down into discipline-specific subsystems and each discipline-specific subsystem is characterised by a model pillar. Only the first (highest) level has an interface to the other pillars via the mechatronic coupling level (Fig. 8).

The functional requirement (FR) of each model pillar is defined by several design parameters (DPs). In the hierarchical design model, one FR at level $i$ can affect several FRs at level $i+1$ via the DPs at level $i$. The design parameters at one level can be classified into two categories, the internal design parameters and the external design parameters. One subset comprises $n_{i+1}$ external parameters representing requirement parameters for the next level. The other internal parameters are exclusively local at the active level for dimensioning the component at this level. The process of defining hierarchical levels must be repeated until elementary FRs (e.g. proven solutions, standard components) with their associated, well known DPs are achieved (Fig. 9 - [36]).

The hierarchical design method is proposed to address complex design tasks, in which the discipline-specific design tasks do not need to be integrated as a whole on the mechatronic level. By analysing the interconnections of the functional parameters, it enables an easy qualification on how a product should be designed to reduce unnecessary iteration loops.

The hierarchical design method supports the concurrent engineering. A complex mechatronic system can be broken down into domain-specific model pillars according to requirement parame- 
Table 6

Evaluation of hierarchical design method.

\begin{tabular}{|c|c|c|}
\hline Design method & Hierarchical design method & \\
\hline Concurrent engineering & A complex mechatronic system can be decomposed into domain-specific model pillars which can be developed simultaneously & Yes \\
\hline $\begin{array}{l}\text { Macro level } \\
\text { collaboration }\end{array}$ & The interfaces between pillars models of different disciplines have been developed in the highest level of hierarchical design model & Yes \\
\hline $\begin{array}{l}\text { Micro-level } \\
\text { collaboration }\end{array}$ & The data derived from the software engineers has not been well integrated during the design process & Partial \\
\hline
\end{tabular}

ters and design parameters addressing multiple disciplines. These domain-specific model pillars can be developed simultaneously. This design method also fulfils the macro-level collaboration because the interfaces between model pillars of different disciplines have been specified in the highest level of hierarchical design model. However, the hierarchical design model does not fully support micro-level collaboration. Although it pays much attention to the information sharing and exchanging between electrical and mechanical design, the data derived from the software engineers has not been well integrated during the design process. Table 6 shows an assessment of hierarchical design method according to the criteria above proposed.

All the design methods discussed above help and guide the engineers in the development of mechatronic system. They are mainly focused on the "process-based problems" solving. However, not all these methods can support the multi-disciplinary collaboration. Product models will be the concerns of the survey introduced in the following section. Product models are used to solve the "design data related problems". Moreover, design process and organisational models have been linked with some product model. Hence, they are also considered as effective supports for the "process-based problems".

\section{Product models for mechatronic engineering}

The main objective of product model is to support PDM functions of PLM throughout the whole product lifecycle. Product model includes all the information that can be accessed, stored, served and reused by stakeholders throughout the entire product lifecycle [37-39].

Nowadays, several product models and their extensions have been proposed. They are not dedicated and implemented specifically for mechatronics. However, they can fairly and efficiently support the design of mechatronic system. Current product models will be presented in the following sections.

\subsection{STEP (STandard for the Exchange of Product)}

STandard for the Exchange of Product model data (STEP) is actually a series of standards, known as ISO 10303 developed by experts worldwide $[40,41]$. Its scope is much broader than that of other existing CAD data exchange formats, such as Initial Graphics Exchange Specification (IGES) which was developed primarily for the exchange of pure geometric data between CAD applications [42]. STEP is intended to handle a much wider range of productrelated data covering the entire life-cycle of a product [43].

As the area of STEP application is extremely broad, it is issued in numerous sections, identified as Parts. The Parts known as APs (Application Protocol) define the scope, context and information requirements of applications [44,45]. STEP has developed more than forty standard APs for product data representation. They reflect the consolidated expertise of major industries for more than twenty years, covering the principal product data management areas for the main industries [46]. In other words, the APs are specific data models based on STEP standard covering the entire lifecycle of a product or/and a certain industrial domain. The STEP APs can be roughly grouped into the three main areas: design, manufacturing and life cycle support.

Nowadays, the STEP APs are widely used in mechanical design domain, such as AP 203, AP 209 and AP 214. Some APs related to electronic/electrical design are also proposed. However, an AP which can systematically support the whole design process of mechatronic system has not been fully developed. The STEP APs which can be used for design of mechatronic system will be introduced in more detail.

STEP AP233 [47] describes the key product data and information for systems engineering that must be exchanged between dissimilar applications for requirements engineering and for systems modelling and simulation [48]. Industries that can benefit from using AP233 are automotive, aerospace, shipbuilding, consumer goods electronics, and others with complex products and processes. AP 239 provides an integration and exchange capability for product life cycle support data [49]. Besides AP 233 and AP 239, other APs related to the different expert knowledge of mechatronic system have been proposed. AP 210 [50] describes the requirements for the design of electrical printed circuit assemblies (PCA). AP 214 [51] specifies the exchange of information between various applications which support the automotive mechanical design process, but it only focuses on the vehicle development process.

STEP standard partially represents the organisational interface, because AP 239 not only integrates the information for defining a complex product and its support solution, but it also represents the planning, the scheduling of the tasks and the management of the subsequent work. However, it remains very generic to support design of mechatronic system and some characteristics and parameters of mechatronic system have not been integrated in this data model. STEP standard partially fulfils macro level interface in some specific disciplines. For example, AP 214 specifies the interfaces between various CAx applications which support the automotive mechanical design process. STEP AP 210 describes the information needed for the design of electrical printed circuit assemblies. As to the micro-level interface, STEP is a powerful standard which supports the exchange of geometric data between CAD applications. It focuses on the electronic/electrical discipline and mechanical discipline but not in an integrated perspective of both disciplines. It does not provide an effective interface to fully support the data exchange in software discipline. Considering the vertical and horizontal changes, STEP allows the designer to exchange the data and information at any time during the product development process, and it also provides a possibility for representing the existing or potential future products, which allows the evolution of product families [52]. An assessment for STEP standard is shown in Table 7.

In this section, the STEP data model and its Application Protocols have been discussed. In the next section, the Core Product Model (CPM) will be presented.

\subsection{CPM (Core Product Model)}

CPM, an abstract model with generic semantics, initially developed at NIST (National Institute of Standards and Technology), can support the full range of PLM information [53]. 
Table 7

Evaluation of STEP standard.

\begin{tabular}{|c|c|c|}
\hline Product model & STEP & \\
\hline $\begin{array}{l}\text { Organisational } \\
\text { interface }\end{array}$ & $\begin{array}{l}\text { STEP AP239 represents the planning and scheduling of complex design tasks, but it is still very generic regarding the specificities in } \\
\text { design of mechatronic system }\end{array}$ & Partial \\
\hline $\begin{array}{l}\text { Macro level } \\
\text { interface }\end{array}$ & $\begin{array}{l}\text { STEP standard only fulfils macro level interface in some specific disciplines (AP } 214 \text { specifies the automotive mechanical design process; } \\
\text { AP } 210 \text { focuses on PCA design...) }\end{array}$ & Partial \\
\hline $\begin{array}{l}\text { Micro-level } \\
\text { interface }\end{array}$ & $\begin{array}{l}\text { It focuses on the electronic/electrical discipline and mechanical discipline but not in an integrated perspective of both disciplines. It does } \\
\text { not provide an effective interface to fully support the data exchange in software discipline }\end{array}$ & Partial \\
\hline Vertical change & STEP allows the designer to exchange the data and information at any time during the product development process & Yes \\
\hline Horizontal change & AP 239 provides a representation of existing or potential future products, which allows managing the data of product families & Partial \\
\hline
\end{tabular}

CPM is based on two principles. First, the key object in the CPM is the artefact. Artefact represents a distinct entity in a product, whether that entity is a component, part, subassembly or assembly. Second, the artefact aggregates three objects representing the artefact's principal aspects: function, form and behaviour. CPM consists of two sets of classes, called object and relationship classes [54,55]. The two sets of classes are equivalent to the Unified Modelling Language (UML) terms of class and association class, respectively [56]. A UML class diagram of the CPM data model is shown in Fig. 10.

As to the multi-disciplinary design (design of mechatronic system), the CPM model does not provide the interfaces between different disciplines. In order to meet the requirements of multidisciplinary design, some extensions have been proposed.

Zha et al. proposed the Extension of CPM Embedded System Model (ESM) which is feature-based approach to the co-design of hardware (HW) and software (SW) in embedded systems [57]. The extended model provides a framework for co-design of feature-based HW/SW components allowing the designer to develop a virtual prototype of embedded system through assembly of virtual components. The interfaces between $\mathrm{HW} / \mathrm{SW}, \mathrm{HW} / \mathrm{HW}$ and SW/SW are proposed in this model (Fig. 11). The interface feature and the co-design of $\mathrm{HW} / \mathrm{SW}$ in embedded system largely expand the CPM model. To a certain extend the embedded system can be fairly assimilated to mechatronic system and ESM partially performed the collaboration between electronic and software disciplines. However, the embedded system is not a real mechatronic system and sometimes it is only a part of mechatronic system.

The Product Family Evolution Model (PFEM) which extends the CPM to the representation of the evolution of product families is developed by [17]. This model represents the independent evolution of products and components through families, series and versions. The information model representing product families is an extension of the CPM and consists of three sub-models: Product Family, Family Evolution, and Evolution Rationale (Fig. 12).

The Mechatronic Device Model (MDM) proposed by [58] is an extension model of CPM. It supports the preliminary design of multiple interaction-state mechatronic devices, where the interactions between the use-environment and the device may have different qualitative structures. This model supports the preliminary design

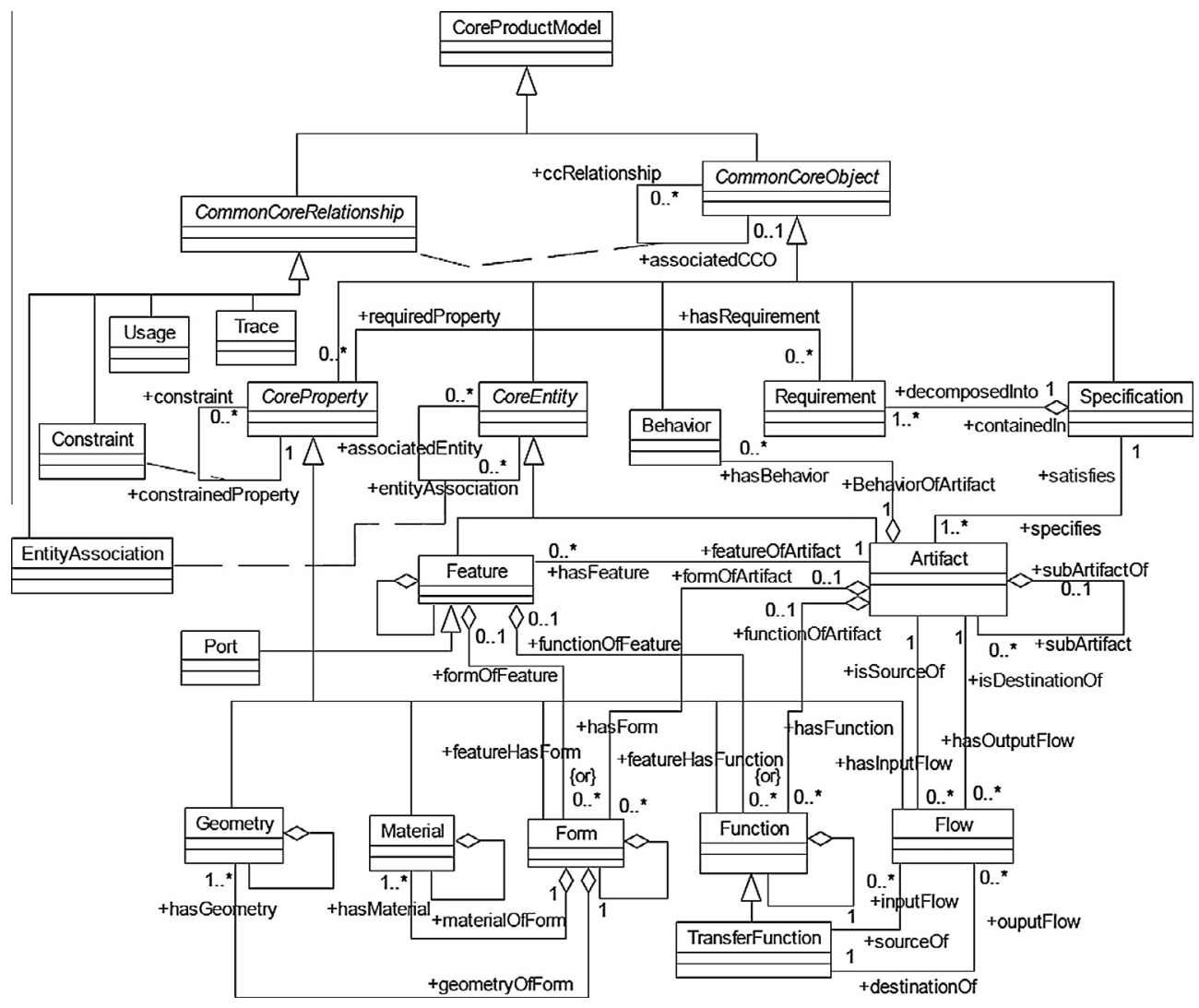

Fig. 10. UML class diagram of the Core Product Model [53]. 


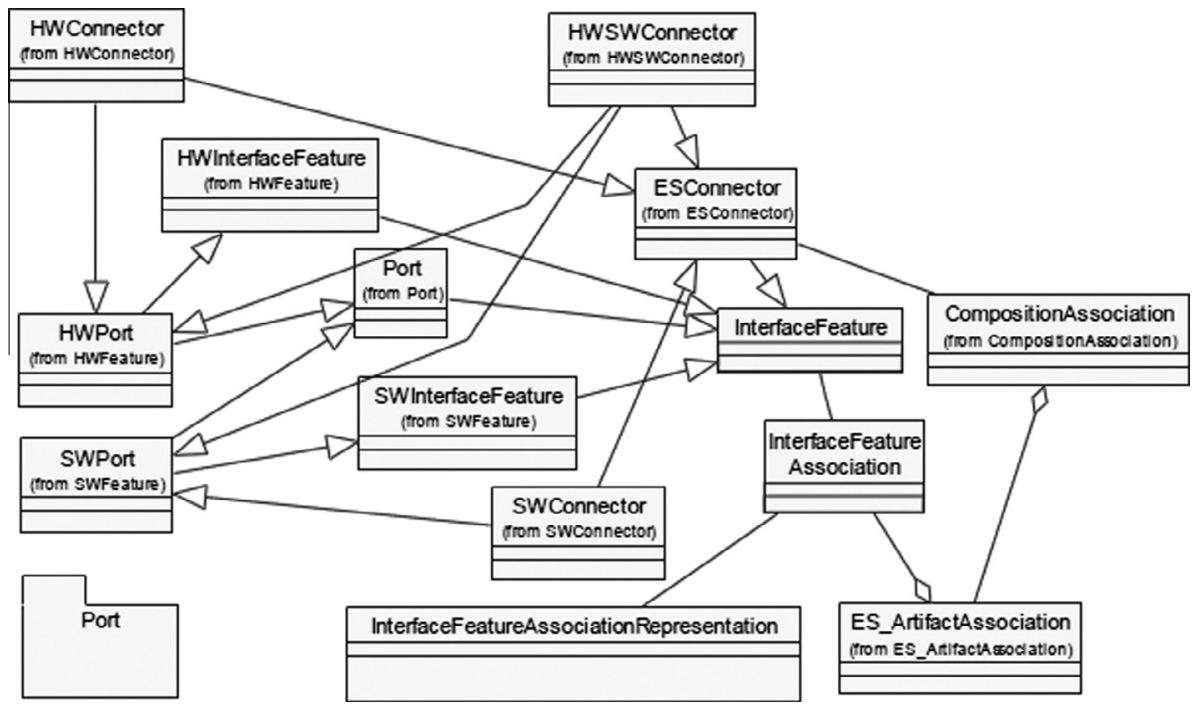

Fig. 11. Interface feature of Embedded System Model [57].

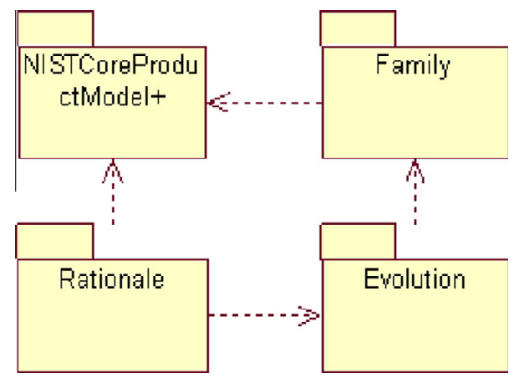

Fig. 12. Main diagram of Product Family Evolution Model [17].

phase in which the desired behaviour and the specification of the internal structure of the mechatronic device will be analysed. As multi-disciplinary collaboration tasks are mainly performed in the "detailed design" phase, in which the principle solutions will be detailed for every components of the system, the MDM does not fulfil collaboration issue (Fig. 13).

In this section, CPM and its extensions have been discussed. CPM proposes an abstract and generic product model for product development. Some extensions of CPM have been proposed to solve certain kinds of problems during the mechatronic design (ESM, PFEM and MDM). However, neither CPM nor its extensions can fully support the mechatronic design.

CPM does not allow the representation of the organisational interface, but the macro level interface and micro-level interface have been integrated in CPM. The extension of CPM Embedded System Model not only defines the interface between hardware and software in embedded systems to meet the requirement of multi-disciplinary collaboration, but an IT platform based on the extension is implemented to fulfil the collaboration between designers. The extension of CPM Product Family Evolution Model provides the description of the change of product family, but the temporal definition has not been explicitly proposed during the product development process. An assessment for CPM is shown in Table 8.

In order to enlarge perspectives on mechatronic expertise, a product model based on the Knowledge Based Engineering (KBE) methodology issued from the MOKA (Methodology and tools Oriented to Knowledge-based engineering Applications) research project will be presented and discussed in the following section.

\subsection{MOKA}

Mechatronic design can be considered as a knowledge intensive engineering process. Large amounts of different kinds of knowledge derived from numerous disciplines are needed during the design process of mechatronic system. The KBE application is proposed to manage the vast amount of data and its flow through complex systems during one product development [59]. It can be seen as an effective tool for capturing knowledge and reusing it during the design process of mechatronic system.

MOKA is a European research project with the aim to develop a methodology and tools to support the deployment of KBE application [60]. MOKA product model is represented thanks to UML. The Structure, Function, Behaviour, Technology and Representation are considered as five basic views for building the product model. The MOKA product model is shown in Fig. 14.

Different from the two product models introduced in the previous subsections, constraints which represent design restrictions are described within the MOKA product model. The constraint concerns the combinations of subsystems in a complex system. It implies the interface between two subsystems [61].

Besides MOKA product model, MOKA also proposes the design process methodology. It defines how to resolve product choices subject to product constraints and the order in which design steps have to be executed and design decisions have to be made [61]. MOKA describes design activities and rules with enough detail to enable them to be automated by UML Activity Diagrams.

Table 9 shows the assessment of MOKA. MOKA provides an organisational interface to describe the design tasks by the Activity Diagrams of MOKA, but it does not propose the models where designers can take into account the status of their own work and their expertise which lead to some change for other disciplines. MOKA can also represent the constraints. Constraints can be represented in the MOKA product model. They imply the interfaces between subsystems. But the constraints existing in mechatronic system have not been specialised. MOKA describes the steps that implement a model instance from a product model, which partially depicts the vertical change of a product. As to the horizontal change, MOKA stores the experience, geometry and data related to a product family in a database.

MOKA has been discussed in this section. It not only provides a product model, but also describes the design process by UML Activity Diagrams. Like MOKA, Product-Process-Organisation 


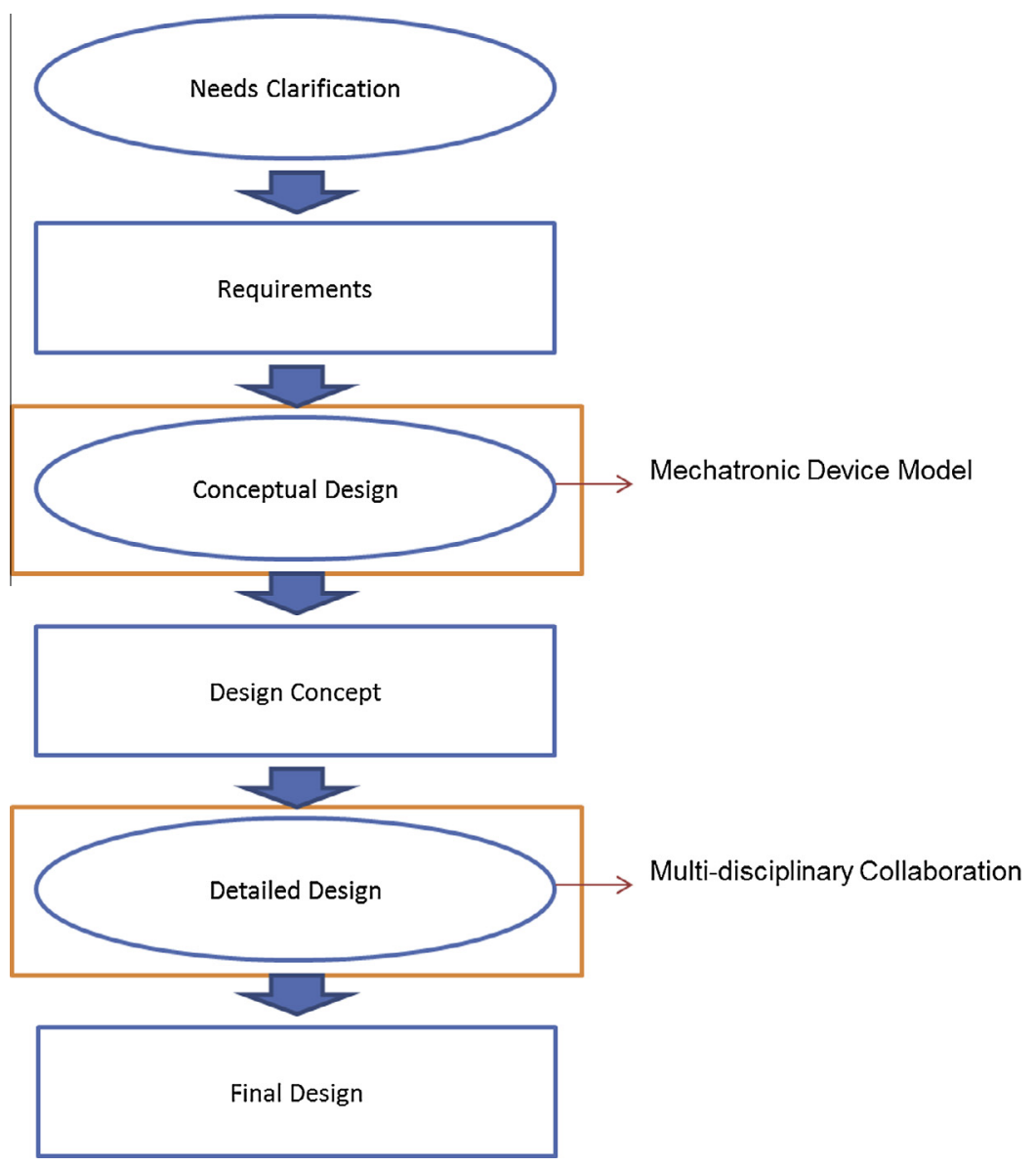

Fig. 13. An abstraction of information flow in design [58].

Table 8

Evaluation of CPM.

\begin{tabular}{|c|c|c|}
\hline Product model & CPM & \\
\hline Organisational interface & CPM does not represent the organisational interface & No \\
\hline Macro level interface & $\begin{array}{l}\text { The Extension of CPM Embedded System Model defines the interface between hardware and software in embedded } \\
\text { systems }\end{array}$ & Partial \\
\hline Micro-level interface & $\begin{array}{l}\text { An IT platform based on CPM Embedded System Model has been established. It allows the designers to develop a virtual } \\
\text { embedded system prototype through the collaboration between designers }\end{array}$ & Partial \\
\hline Vertical change & $\begin{array}{l}\text { CPM supports all the information throughout the full range of product lifecycle, but temporal dynamics of the product } \\
\text { definition has not been explicitly proposed during the product development process }\end{array}$ & Partial \\
\hline Horizontal change & The extension of CPM Product Family Evolution Model provides the representation of the change of product families & Yes \\
\hline
\end{tabular}

model (PPO) model also focuses on the organisational process. The following section will present the PPO model.

\subsection{PPO (Product-Process-Organisation) model}

Design process of mechatronic system requires collaboration among different disciplines and designers. The collaboration during design process can be considered as a problem that has to be solved. Therefore, the process and the organisational models have been linked with the product model.

In order to fulfil these aims, the IPPOP (Integration of Product, Process and Organisation for improvement of engineering Performance) project has developed the PPO model which describes information of product, process and organisation. It enhances interoperability of heterogeneous expert tools during the product development process [62]. The product model developed in the IPPOP project is shown in Fig. 15. It consists of 4 main concepts: Component, Interface, Function and Behaviour.
An interface class is described in the product model by the way a component (mechanical, electrical, etc.) may be linked to another. Although the interface class is derived into Common Interfaces $(\mathrm{CI})$, Alternative Interfaces $(\mathrm{AI})$ and View Interfaces (VI), it needs to be further specified for mechatronic system and the collaboration among different disciplines has to be fully implemented in the product model.

In the PPO model, product model is extended according to the process and organisation models. In the process model (Fig. 16), a particular activity is defined to describe collaborative actions (Collaborative Activity) in which the team members may collaborate in order to solve a conflict during the design process.

Moreover, the PPO model offered a traceability of the evolution of the design process in the whole design organisation. This traceability is based on the versioned technical data to take into account the temporal dynamic of the product definition. It is characterised by its maturity degree ("Maturity") and a "Status" as shown in Fig. 16. 


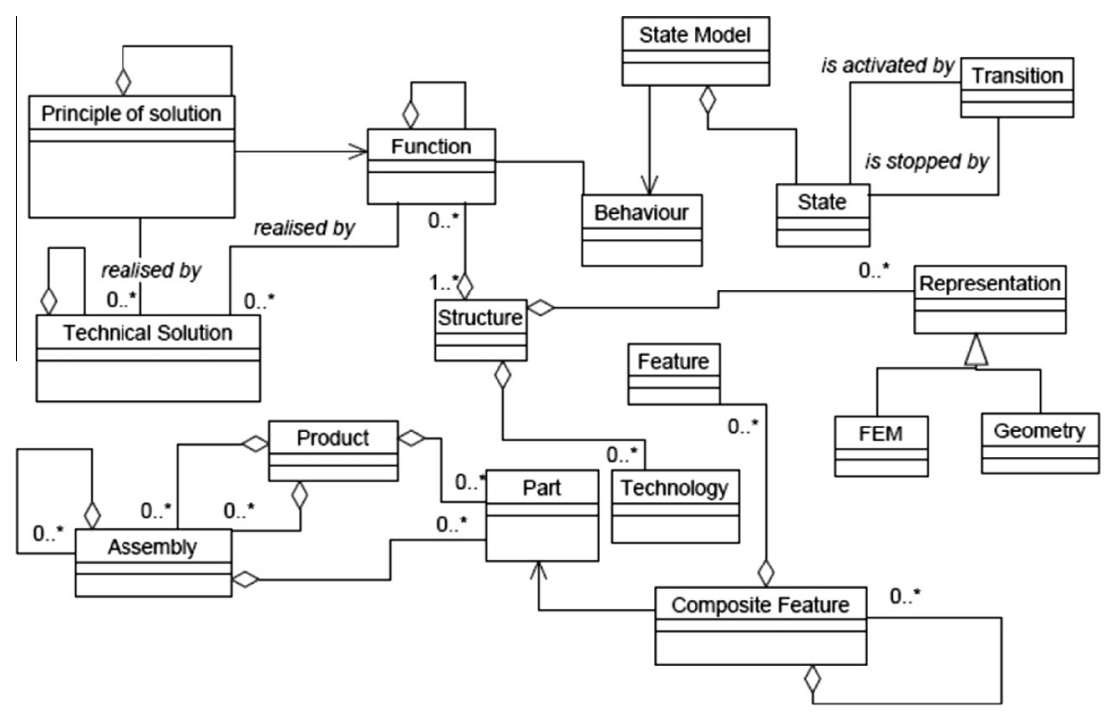

Fig. 14. MOKA product model.

Table 9

Evaluation of MOKA.

\begin{tabular}{|c|c|c|}
\hline Product model & MOKA & \\
\hline Organisational interface & $\begin{array}{l}\text { MOKA provides an interface to describe the design tasks and rules by Activity Diagrams of MOKA, but it does not offer the } \\
\text { design environment where engineers can take into account the status of their own design and their expertise which lead to } \\
\text { some change for other disciplines }\end{array}$ & Partial \\
\hline Macro level interface & Constraint has been represented in the MOKA product model which implies the interface between two subsystems & Partial \\
\hline Micro-level interface & MOKA does not provide an interface for data exchange between engineers & No \\
\hline Vertical change & $\begin{array}{l}\text { MOKA describes the steps that implement a model instance from a product model, which partially depicts the vertical } \\
\text { change of a product }\end{array}$ & Partial \\
\hline Horizontal change & $\begin{array}{l}\text { MOKA is one of approaches for Knowledge Based Engineering by which the experience, geometry and data that relate to a } \\
\text { product family can be stored in database }\end{array}$ & Yes \\
\hline
\end{tabular}

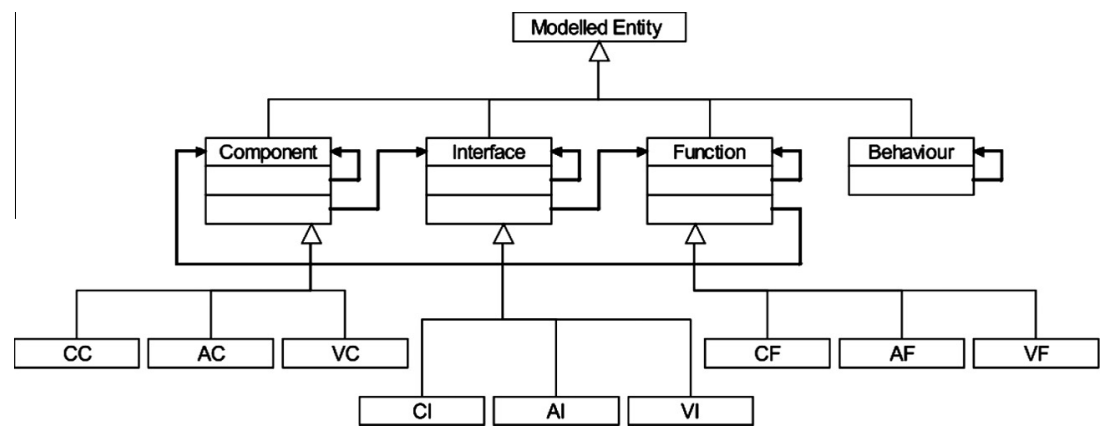

Fig. 15. Product model class diagram [63].

In the PPO model, the organisational interface has been well specified. A decision framework has also been developed in the organisational model. It defines different horizons for the decision-making and manages the design process according to the engineers' needs. The PPO model also establishes an interface by which subsystems can be linked to each other, but this interface should be further specialised for mechatronic system modelling. A prototype of software supporting the PPO model has been developed. It can be underlined that it fulfils the micro-level interface so that the designers can find the information necessary to achieve their own tasks. As to the vertical change, technical data is considered as versioned to take into account the temporal dynamics of the product definition. However, the information related to a product family has not been explicitly proposed during the product development process to support the horizontal change of a mechatronic system. An evaluation of PPO is shown in Table 10.

The PPO model is considered as an effective support for the development process of a complex system because the data of product, process and organisation during the design process have been taken into account by the PPO model, but it should be further specialised for mechatronic system design. As shown with recent PPO model developments, PPO is generally considered as an extensible data model [65]. Hence, a special extension for design of mechatronic system can be developed based on PPO model.

Numerous product models have been presented and discussed in the above sections. The following section will summarise the assessment of different design approaches, including the design 


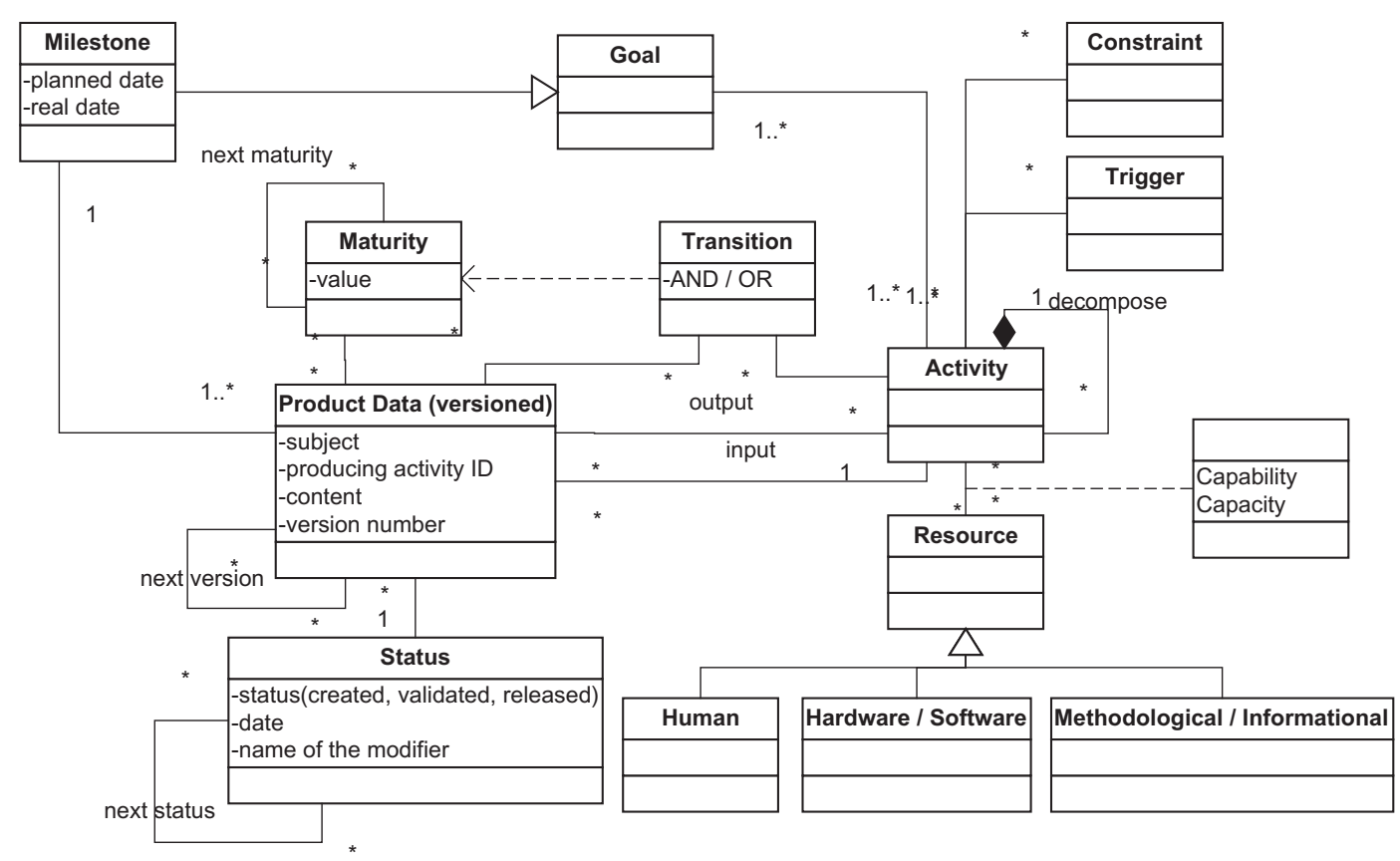

Fig. 16. Process model developed during the IPPOP project [64].

Table 10

Evaluation of PPO

\begin{tabular}{|c|c|c|}
\hline Product model & PPO & \\
\hline $\begin{array}{l}\text { Organisational } \\
\text { interface }\end{array}$ & $\begin{array}{l}\text { A decision framework has been developed in the organisational model, which defines different horizons for the decision-making and } \\
\text { manages the design process according to the engineers' needs }\end{array}$ & Yes \\
\hline $\begin{array}{l}\text { Macro level } \\
\text { interface }\end{array}$ & $\begin{array}{l}\text { An interface class is proposed by which a subsystem (mechanical, electrical and etc.) may be linked to another, but this model is very } \\
\text { generic and should be further specialised for mechatronic system modelling }\end{array}$ & Partial \\
\hline $\begin{array}{r}\text { Micro-level } \\
\text { interface }\end{array}$ & $\begin{array}{l}\text { A prototype of software supporting the PPO model has been developed during the IPPOP project. An engineer can find all information } \\
\text { necessary to achieve his task by using a specific Graphical User Interface (GUI) }\end{array}$ & Yes \\
\hline Vertical change & Technical data is considered as versioned to take into account the temporal dynamics of the product definition & Yes \\
\hline Horizontal change & The information related to a product family has not been explicitly proposed during the product design process & Partial \\
\hline
\end{tabular}

methods and the product models for design of mechatronic system.

\section{Assessment of studied design concerns}

From the survey above, the two concerns for design of mechatronic system are highlighted as "design method" and "product model", which are respectively dedicated to solve the "Processbased problems" and the "Design data-related problems". Although there have been efforts that address such two kinds of concerns. Some challenges still exist during the design process of mechatronic system. Therefore, both design method and product model should be further improved to meet the requirement of integrated design.

In this section, the design concerns presented above will be assessed and discussed according to specific criteria. The assessment will start with the design methods.

\subsection{Assessment of studied design methods}

Design of mechatronic system requires a high degree of integration, and the complex mechatronic system is often broken down into simpler subsystems or components. Meanwhile, the complex design project calls for the resources management and coordination of project team members in order to be successful. Hence, the collaboration among different expertise and disciplines during the design process of mechatronic system plays a key role to ensure that the results of their efforts are successful, especially to obtain an integrated system.

Concurrent engineering approach (1) of product development process is of great importance, because the development leadtimes can be drastically reduced through the design tasks carried out in parallel. However, organising the concurrency of tasks in order to achieve the resources management and coordination of project team members is still a critical issue, especially to get a fully integrated design.

Two kinds of collaboration levels are considered. The first one, called in this paper macro level collaboration (2), emphasises the discipline homogeneous collaboration. The second one focuses on the collaboration of individuals, in other words, the interaction between projects team members, which is called in this paper micro-level collaboration (3).

In this subsection dealing with design methods, three criteria of collaboration have been chosen for the evaluation: (1) Integrated design and concurrent engineering; (2) Macro level collaboration; (3) Micro-level collaboration. The assessment is summarised in Table 11.

Table 11 shows the assessment of the design methods according to the above proposed criteria. Except the sequential design 
Table 11

Assessment of the design methods regarding needs of multi-disciplinary collaboration.

\begin{tabular}{|c|c|c|c|}
\hline Design method & Concurrent engineering & Macro level collaboration & Micro-level collaboration \\
\hline Sequential design model & No & Yes & No \\
\hline V-model & Yes & Partial & No \\
\hline VDI 2206 & Yes & Partial & No \\
\hline RFLP & Yes & Yes & Partial \\
\hline Hierarchical design model & Yes & Yes & Partial \\
\hline
\end{tabular}

process, the other design methods allow the concurrent engineering and integrated design. There exist explicit links between the expert components in the sequential design process, RFLP method and hierarchical design method. So these three methods can fully support the macro level collaboration. However, only the RFLP method and hierarchical design method partially support the micro-level collaboration during the design process.

Based on the assessment outcomes shown in Table 11, the current design methods partially support the design of mechatronic system, but none of them can help project team members to achieve the integrated design. On one hand, although most of these design methods allow an effective concurrent engineering, the detailed design phase has not been clarified. On the other hand, more attention should be paid on the interfaces to help the engineers to accomplish both the macro level collaboration and the micro-level collaboration.

Product model includes all the information that can be accessed, stored, served and reused by stakeholders throughout the entire product lifecycle. As some product models have integrated a part of the organisational model or process model, they are also considered as an effective tool to support the design method. The assessment outcomes of different product models will be detailed in the following section.

\subsection{Assessment of product models}

In this section, the product models will be assessed according to specific criteria-interface and product change.

Considering multi-disciplinary design, three criteria linked with the concept of interface are proposed in this paper. (1) Organisational interfaces can guide all the design tasks and support the collaboration during the design process. (2) macro level interface, which is a special link between components defined by the different disciplines involved in the design of mechatronic system, and (3) micro-level interface, which allows the experts to use the information or data from other disciplines.

Considering the product change, two criteria have been proposed to deal with the different kinds of changes: (4) vertical change and (5) horizontal change.

In this subsection, five criteria dealing with interface and product change have been chosen for assessing the product models: (1) organisational interface; (2) macro level interface; (3) micro-level interface; (4) vertical change; (5) horizontal change. The assessment of the product models based on these criteria will be discussed in the section below.

Table 12 shows the assessment of the studied product models according to the proposed criteria. With the purpose of organising design tasks more efficiently, the organisational interface has been included in STEP, MOKA and PPO. The product models, such as STEP, CPM and PPO, have partially developed the interfaces (macro level interface and micro-level interface) to meet the requirements of collaboration between various experts and disciplines. All the product models discussed in this paper take partially product change into account.

Several criteria have been chosen to assess a selection of design methods and product models in this section. Table 11 has shown that current design methods for mechatronic system cannot fully achieve the integrated design. Some product models provide the organisational interface, the macro level interface and the microlevel interface to support the concurrent engineering, the macro level collaboration and the micro-level collaboration respectively. A synthesis on assessment of design method and product model will be presented in the following section.

\section{Synthesis of design methods and product models}

Several design methods and product models have been surveyed and assessed according to a proposed list of specific criteria. A synthesis will be given according to the survey and assessment outcomes in this section.

\subsection{Product model as an effective support for design method}

In Section 5.1, different design methods have been assessed according to three specific criteria: concurrent engineering, macro level collaboration and micro-level collaboration. None of the design methods have fully met these criteria. However, Section 5.2 shows that certain interfaces which allow concurrent engineering, integrated design and multi-disciplinary collaboration have been implemented in some product models. Even process and organisation models have been integrated into some product models.

Concurrent engineering greatly reduces the design lead-times of mechatronic design. The assessment outcomes in Section 5.1 show that most of design methods meet the concurrent engineering principles. However, the mechatronic system becomes increasingly complex. The design process should be broken down into detailed tasks which require multi-disciplinary collaboration. How to organise these design tasks in a concurrent way is still a critical issue. In order to solve this issue, some product models have taken organisational interfaces into account. Section 5.2 shows that the organisational interfaces have been partially met in STEP and MOKA model. In the IPPOP project, process model and organisation model have been fully implemented (PPO model).

Table 12

Evaluation of the different data models.

\begin{tabular}{|c|c|c|c|c|c|}
\hline Product model & Organisational interface & Macro level interface & Micro-level interface & Vertical change & Horizontal change \\
\hline STEP & Partial & Partial & Partial & Yes & Partial \\
\hline CPM & No & Partial & Partial & Partial & Yes \\
\hline MOKA & Partial & Partial & No & Partial & Yes \\
\hline PPO & Yes & Partial & Yes & Yes & Partial \\
\hline
\end{tabular}


Macro level collaboration pays special attention to the link between subsystems in order to achieve a strong integration of them. It can bring the system perspective as a synergetic integration. With the purpose of two subsystems to be interconnected, the macro level interface can greatly enable the macro level collaboration. Section 5.2 has shown that STEP, CPM and PPO models have partially fulfilled the macro level interface.

The micro-level collaboration takes place among the design team members and is always performed thanks to a dedicated IT platform. Some product models, such as STEP, CPM and PPO models, allow implementing such IT platform for exchange of disciplinary data derived from design and simulation tasks.

Considering that none of the design methods can completely meet the criteria of collaboration, certain product models can be adopted during the design process to help the engineers achieve an integrated design. For instance, the assessment outcomes in Section 5.1 have shown that the RFLP method cannot fully support micro-level collaboration, but the micro-level interface have been completely defined in PPO model. Moreover, a mapping can be implemented between the function level of RFLP and the function class of PPO model, which makes the integration of RFLP method and PPO model becomes possible at macro level. In summary, product model is an effective support for design method, but a lot of work still to be done in the future. Future research will be presented in the following section.

\subsection{Future work}

Future work should be divided into three parts. First of all, special attention should be paid to the organisational interface in the design method. The second issue is to focus on improving the product model for the design of mechatronic system with a high level integration (physical and functional integration). Last, mappings should be constructed between design method and product models in order to achieve a global concurrent engineering and integrated design approach.

First, organisational interface helps engineers to organise the design tasks properly and to achieve an effective concurrent design approach. Two kinds of organisational interfaces should be further studied in the future. The first one exists between the requirements and the principal solution. The second kind of organisational interface improves the exchange among different design team members to notify the others on how their design solution affects the other one.

Second, as for the product model, on one hand, the three kinds of interfaces above proposed should be further improved to meet the collaboration requirements. On the other hand, much work should be done to improve the product change management in the product model in order to reduce the lead-times and the development cost.

Last, as the product model can be a valuable support for mechatronic design, it should be focus on how to integrate the product model into the current design process. Although some mappings can be implemented between design method and product model (e.g. Function Level of RFLP and Function Class of PPO model), the current product models cannot be completely adapted to the design method. In the future work, in order to achieve a global concurrent engineering and integrated design approach, design method and product model should be further merged so that more mappings can be built between them.

\section{Conclusion}

Integrated design for mechatronic system plays an increasingly key role for more and more smart products. According to the principles of integrated design, engineers intend to develop a mechatronic system with a high level integration (integrated mechatronic system) through a well-organised design method (integrated design method). As a result, two main categories of issue have been pointed out: the "Process-based problems" and the "Design data-related problems". Several approaches to overcome these problems have been put forward. To solve "Process-based problems", a dynamic perspective is generally used to present how collaboration can be improved during the mechatronic design. For "Design data-related problems", solutions generally come from product models and how to structure the data and documents management of PLM throughout the whole product lifecycle.

The design tasks in mechatronic engineering are becoming more and more collaborative and integrated. Nowadays simply manage the progress of design process is not enough. The organisation of design project support by the design method should be taken into account. The conclusion drawn from this paper is that product model is an effective support for design process of mechatronic system. Even design process and organisation models have been linked with some product models (e.g. PPO model). Making use of the product model can help to achieve a better collaboration in the design process, but how to integrate the product model into the current design process effectively and efficiently remain a critical issue.

\section{Acknowledgment}

This work was carried out in the framework of the LabCom DIMEXP, which was funded by the French government, through the "Economic impact of research and competitiveness" program managed by the French National Agency of Research (Reference ANR-13-LAB1-0006-01).

\section{References}

[1] J.E. Carryer, R.M. Ohline, T.W. Kenny, Introduction to Mechatronic Design, Prentice Hall, 2011.

[2] M. Tomizuka, Mechatronics: from the 20th to 21st century, Control Eng. Pract. 10 (2002) 877-886.

[3] R. Isermann, Mechatronic Design Approach, in: R.H. Bishop (Ed.), The Mechatronics Handbook, CRC Press, 2002. LLC.

[4] D. Shetty, R.A. Kolk, Mechatronics system design, in: Mechatronics System Design: SI, 2010: pp. 1-40.

[5] H.-P. Schöner, Automotive mechatronics, Control Eng. Pract. 12 (2004) 13431351.

[6] G. Sohlenius, Concurrent engineering, CIRP Ann. - Manuf. Technol. 41 (1992) 645-655.

[7] S. Tichkiewitch, De la CFAO à la conception intégrée, Revue Internationale de C.F.A.O. et D'infographie. 9 (1994) 609-621.

[8] M. Abramovici, F. Bellalouna, Service oriented architecture for the integration of domain-specific PLM systems within the mechatronic product development, in: Proceedings of the 7th International Symposium on Tools and Methods of Competitive Engineering (TMCE 2008), Izmir, Turkey, 2008, pp. 941-953.

[9] M. Abramovici, F. Bellalouna, Integration and complexity management within the mechatronics product development, in: Advances in Life Cycle Engineering for Sustainable Manufacturing Businesses, 2007, pp. 113-118.

[10] M. Bricogne, L. Petit, A.M. Meyine, N. Troussier, B. Eynard, D. Schweitzer, mechatronics issues for specification of PLM functionalities and features, in: MECATRONICS2010, Yokohama, Japan, 2010.

[11] O. Penas, R. Plateaux, J.-Y. Choley, A. Rivière, The different complexity levels in mechatronic design process, in: 3rd International Conference on Software, Knowledge, Information Management and Applications SKIMA, Fès, Morocco, 2009 .

[12] L. Wang, W. Shen, H. Xie, J. Neelamkavil, A. Pardasani, Collaborative conceptual design state of the art and future trends, Comput. Aided Des. 34 (2002) 981 996.

[13] J. Wikander, M. Törngren, M. Hanson, Emphasizing team building in a problem- and project-based curriculum to meet the challenges of the interdisciplinary nature of this field, Robot. Automat. Mag. 8 (2001) 20-26.

[14] K. Thramboulidis, Model-integrated mechatronics-toward a new paradigm in the development of manufacturing systems, IEEE Trans. Industr. Inf. 1 (2005) 54-61.

[15] B. Bettig, J.K. Gershenson, The representation of module interfaces, Int. J. Product Dev. 10 (2010) 291-317. 
[16] X.F. Zha, H. Du, Knowledge-intensive collaborative design modeling and support, Comput. Ind. 57 (2006) 39-55.

[17] F. Wang, S.J. Fenves, R. Sudarsan, R. Sriram, P. Group, M. Systems, et al., Towards modeling the evolution of product families, in: ASME Computers and Information In Engineering Conference, Chicago, USA, 2003.

[18] B.S. Blanchard, System Engineering Management, John Wiley \& Sons, 2012.

[19] B.W. Boehm, Software Engineering Economics, Prentice Hall, 1981.

[20] B.W. Boehm, A spiral model of software development and enhancement, Computer 21 (1988) 61-72.

[21] K. Forsberg, H. Mooz, System engineering for faster, cheaper, better, in: Proceedings of the 9th Annual International Symposium of the INCOSE1998, Vancouver, Canada, 1998: pp. 1-8.

[22] G.A. Hazelrigg, Systems Engineering: An Approach to Information-Based Design, Prentice Hall, Upper Saddle River, 1996.

[23] G. Pahl, W. Beitz, J. Feldhusen, K.H. Grote, Engineering Design: A Systematic Approach, Springer, 2007.

[24] Q. Li, W.J. Zhang, L. Chen, Design for control - a concurrent engineering approach for mechatronic systems design, IEEE/ASME Trans. Mechatron. 6 (2001) 161-169.

[25] N. Gautam, N. Singh, Lean product development: maximizing the customer perceived value through design change (redesign), Int. J. Prod. Econ. 114 (2008) 313-332.

[26] A.A. Alvarez Cabrera, M.J. Foeken, O.A. Tekin, K. Woestenenk, M.S. Erden, B. De Schutter, et al., Towards automation of control software: a review of challenges in mechatronic design, Mechatronics 20 (2010) 876-886.

[27] Department of Transportation, Systems Engineering for Intelligent Transportation Systems, Washington, DC, USA, 2007.

[28] C. Koch, A. Spröwitz, T. Ströhla, Project course "Design of Mechatronic Systems", in: IEEE International Conference on Mechatronics (ICM 2006), Budapest, Hungary, 2006, pp. 2-5.

[29] A.B. Fotso, R. Wasgint, R. Achim, State of the art for mechatronic design concepts, in: 8th IEEE/ASME International Conference on Mechatronic and Embedded Systems and Applications, Suzhou, China, 2012, pp. 232-240.

[30] J. Bathelt, A. Jonsson, C. Bacs, S. Dierssen, M. Meier, Applying the new VDI Design Guideline 2206 on mechatronic systems controlled by a PLC, in: International Conference on Engineering Design (ICED 05), Melbourne, Australia, 2005, pp. 1-14.

[31] V.S. Vasi, M.P. Lazarevic, Standard industrial guideline for mechatronic product design, FME Trans. 36 (2008) 103-108.

[32] S. Kleiner, C. Kramer, Model based design with systems engineering based on RFLP using V6, in: Proceedings of the 23rd CIRP Design Conference, Bochum, Germany, 2013, pp. 93-102.

[33] J. Lefèvre, S. Charles, M. Bosch-Mauchand, B. Eynard, É. Padiolleau, Towards multidisciplinary modeling and simulation: Interoperability issues and challenges for mechatronic engineering, in: Proceedings of the 9th International Symposium on Tools and Methods of Competitive Engineering (TMCE'2012), Karlsruhe, Germany, 2012.

[34] G. Beier, A. Figge, R. Müller, U. Rothenburg, R. Stark, Supporting product development through cross-discipline dependency-modeling - novel approaches for traceability-usage, Lect. Notes Inform. Theor. 1 (2013) 21-28.

[35] P. Hehenberger, M. Follmer, R. Geirhofer, K. Zeman, Model-based system design of annealing simulators, Mechatronics 23 (2013) 247-256.

[36] P. Hehenberger, F. Poltschak, K. Zeman, W. Amrhein, Hierarchical design models in the mechatronic product development process of synchronous machines, Mechatronics 20 (2010) 864-875.

[37] S. Rachuri, S.J. Fenves, R.D. Sriram, F. Wang, A product information modeling framework for product lifecycle management, Comput. Aided Des. 37 (2005) 1399-1411.

[38] X. Tang, H. Yun, Data model for quality in product lifecycle, Comput. Ind. 59 (2008) 167-179.

[39] B. Eynard, T. Gallet, P. Nowak, L. Roucoules, UML based specifications of PDM product structure and workflow, Comput. Ind. 55 (2004) 301-316.

[40] SCRA STEP Application. Step Application Handbook ISO 10303 Version 3, Hand Book; 2006.

[41] ISO10303-1. Overview and Fundamental Principles, ISO; 1994.

[42] S.J. Kemmerer, STEP: The grand experience, US Department of Commerce, Technology Administration, National Institute of Standards and Technology, Gaithersburg, USA, 1999.
[43] M.J. Pratt, Introduction to ISO 10303 - the STEP standard for product data exchange, J. Comput. Inform. Sci. Eng. 1 (2001) 102-103.

[44] P. Gu, K. Chan, Product modelling using STEP, Comput. Aided Des. 27 (1995) $163-179$.

[45] G.L. Smith, Utilization of STEP AP 210 at the boeing company, Comput. Aided Des. 34 (2002) 1055-1062.

[46] R. Jardim-Goncalves, N. Figay, A. Steiger-Garção, Enabling interoperability of STEP application protocols at meta-data and knowledge level, Int. J. Technol. Manage. 36 (2006) 402-421.

[47] ISO10303-233, Industrial Automation Systems and Integration - Product Data Representation and Exchange - Part 233: Application Protocol: Systems Engineering, ISO, 2012.

[48] J. Lefèvre, S. Charles, M. Bosch-Mauchand, B. Eynard, E. Padiolleau, Multidisciplinary modelling and simulation for mechatronic design, J. Des. Res. 12 (2014) 127-144.

[49] T. Paviot, V. Cheutet, S. Lamouri, A PLCS framework for PDM/ERP interoperability, Int. J. Prod. Lifecycle Manage. 5 (2011) 295-313.

[50] ISO10303-210, Industrial Automation Systems and Integration - Product Data Representation and Exchange - Part 210: Application Protocol: Electronic Assembly, Interconnect, and Packaging Design, ISO, 2011.

[51] ISO10303-214, Industrial Automation Systems and Integration - Product Data Representation and Exchange - Part 214: Application Protocol: Core Data for Automotive Mechanical Design Processes, ISO, 2010.

[52] ISO10303-239, Industrial Automation Systems and Integration - Product Data Representation and Exchange - Part 239: Application Protocol: Product Life Cycle Support, ISO, 2005.

[53] S.J. Fenves, S. Foufou, C. Bock, R.D. Sriram, CPM: a core model for product data, J. Comput. Inf. Sci. Eng. (2006) 1-14.

[54] S.J. Fenves, A Core Product Model for Representing Design Information, Gaithersburg, USA, 2002.

[55] S.J. Fenves, S. Foufou, C. Bock, R. Sudarsan, N. Bouillon, R.D. Sriram, CPM2: A Revised Core Product Model for Representing Design Information, Gaithersburg, USA, 2004.

[56] G. Booch, J. Rumbaugh, I. Jacobson, The Unified Modeling Language User Guide, Addison-Wesley, 1998.

[57] X.F. Zha, S.J. Fenves, R.D. Sriram, A feature-based approach to embedded system hardware and software co-design, in: ASME Design Engineering Technical Conference, Long Beach, USA, 2005, pp. 1-12.

[58] C. Xu, S.k. Cupta, Z. Yao, M. Gruninger, Towards computer-aided conceptual design of mechatronic devices with multiple interaction-states, in: Proceedings of the ASME Design Engineering Technical Conferences, Long Beach, CA, USA, 2005.

[59] C.B. Chapman, M. Pinfold, The application of a knowledge based engineering approach to the rapid design and analysis of an automotive structure, Adv. Eng. Softw. 32 (2001) 903-912.

[60] K. Oldham, S. Kneebone, M. Callot, A. Murton, R. Brimble, MOKA - a methodology and tools oriented to knowledge-based engineering applications, in: Proceedings of the Conference on Integration in Manufacturing, Goteborg, Sweden, 1998, pp. 198-207.

[61] MML Working Group, MOKA user guide (MOKA modelling language core definition), Technical Report, 2000.

[62] F. Noël, L. Roucoules, The PPO design model with respect to digital enterprise technologies among product life cycle, Int. J. Comput. Integr. Manuf. 21 (2008) 139-145.

[63] F. Noël, L. Roucoules, D. Teissandier, Specification of product modelling concepts dedicated to information sharing in a collaborative design contexte, in: 5th International Conference on Integrated Design and Manufacturing in Mechanical Engineering (IDMME'04), Bath, UK, 2004, pp. 135-146.

[64] P. Nowak, B. Rose, L. Saint-Marc, M. Callot, B. Eynard, L. Gzara-Yesilbas, et al., Towards a design process model enabling the integration of product, process and organisation, in: 5th International Conference on Integrated Design and Manufacturing in Mechanical Engineering (IDMME'04), Bath, UK, 2004: pp. 91-103.

[65] J. Le Duigou, A. Bernard, N. Perry, Framework for product lifecycle management integration in small and medium enterprises networks, Comput.-Aided Des. Appl. 8 (2011) 531-544. 